\title{
Effects of Nitrogen, Phosphorus and Potassium on Yield of Sweet Corn
}

\author{
Hanfeng Xiong 1,a, Yousheng Xiong 2, b, Guobin Zhang ${ }^{3}$, Zhengdong Peng ${ }^{4}$, \\ Shaohua $\mathrm{He}^{4}$, Dabin $\mathrm{Xu}^{2}$ and Wei $\mathrm{Liu}^{2}$ \\ ${ }^{1}$ Ezhou Polytechnic, Ezhou 436000, China; \\ ${ }^{2}$ Plant Protection and Soil Fertilizer Institute, Hubei Academy of Agricultural Sciences, Wuhan \\ 430064, China; \\ ${ }^{3}$ Soil and Fertilizer Station of Gucheng County in Hubei Province, Gucheng 441700, China; \\ ${ }^{4}$.Wuhan Agricultural Technical Centre in Hannan District, Wuhan 430090, China \\ E-mail: ${ }^{a} x h f e n g 987 @ 163 . c o m{ }^{b}$ Corresponding author: yshxiong@126.com
}

Keywords: "3414 "field experiments, Sweet corn, Fertilization, Yield.

\begin{abstract}
In order to study the effects of different amount of nitrogen, phosphorus, potassium and all the fertilization ratio on sweet corn yield, "3414" design theory was applied to set sweet corn fertilizer efficiency test in Wuhan city modern agricultural experiment and demonstration garden. Result showed that the yield of sweet corn was significantly affected by different amounts of fertilizer and different fertilization ratio. The yield of treatment7 (N2P3K2) was the highest, reaching $13477.5 \mathrm{~kg} / \mathrm{hm} 2$, when that of no fertilizer (NOP0K0) treatment was $10870.5 \mathrm{~kg} / \mathrm{hm} 2$. The difference of yield was significant. Compared with the different dosage of nitrogen and phosphorus and potassium, it found that while the other two fertilizes kept unchanged only increased a single use of another fertilizer, the sweet corn yields increased with the fertilizer at first and then decreased when continued to improve the amount of the fertilizer treatments. Results showed that the treatment of no potassium had a notable effect on sweet corn yield. Contrasted with the nutrients deficiency no phosphorus treatment had less effect on sweet corn yield and no nitrogen treatment had minimal effect on sweet corn yield. Potassium fertilizer is the key factors. It should be consideration of the reasonable application of fertilizer in fields.
\end{abstract}

\section{Introduction}

The growth of sweet corn is large and the growth speed is fast. Therefore, the growth and development of sweet corn needs a large amount of nutrient absorption, and the intensity of nutrient supply is also high. The serious problems such as nitrogen, phosphorus, potassium fertilizer use rate and unreasonable ratio and the decrease of nutrient use efficiency are the important reasons for low yield and instability of maize ${ }^{[1]}$. In recent years, a large number of "3414" field fertilizer efficiency data has been accumulated in different agricultural ecological areas ${ }^{[2-5]}$. The application of "3414" field experiments to study the amount of fertilizer and fertilizer proportion of sweet corn is less reported ${ }^{[6]}$. In this study, the "3414" field experiment was conducted to study the amount of fertilizer and fertilizer rate in sweet corn cultivation, In order to improve fertilizer utilization, reduce farmers' input, increase economic benefits and protect the ecological environment.

\section{Materials and Methods}

\subsection{Experimental design}

Experiment treatment repeat 3 times. Plot area is $20 \mathrm{~m}^{2}$. Plot is Random block arrangement. The experiment is arranged in Wuhan modern agricultural experiment demonstration garden. The varieties of tested crops were sweet and waxy. Sowing time: July 20, 2015. Harvest time: October 8th，2015. P, $\mathrm{K}$ all base application, N 60\% base application, 40\% Top-dressing. 
TABLE 1.3414 test fertilization scheme

\begin{tabular}{|c|c|c|c|c|}
\hline \multirow{2}{*}{ number } & \multirow{2}{*}{ Factor level } & \multicolumn{3}{|c|}{ Nutrient application $(\mathrm{kg} / \mathrm{hm} 2)$} \\
\cline { 3 - 5 } & & $\mathrm{N}$ & $\mathrm{P} 2 \mathrm{O}$ & $\mathrm{K} 20$ \\
\hline 1 & N0P0K0 & 0 & 0 & 0 \\
\hline 2 & N0P2K2 & 0 & 22.5 & 45 \\
\hline 3 & N1P2K2 & 90 & 22.5 & 45 \\
\hline 4 & N2P0K2 & 180 & 0 & 45 \\
\hline 5 & N2P1K2 & 180 & 11.25 & 45 \\
\hline 6 & N2P2K2 & 180 & 22.5 & 45 \\
\hline 7 & N2P3K2 & 180 & 33.75 & 0 \\
\hline 8 & N2P2K0 & 180 & 22.5 & 22.5 \\
\hline 9 & N2P2K1 & 180 & 22.5 & 67.5 \\
\hline 10 & N2P2K3 & 180 & 22.5 & 45 \\
\hline 11 & N3P2K2 & 270 & 22.5 & 22.5 \\
\hline 12 & N1P1K2 & 90 & 11.25 & 22.5 \\
\hline 13 & N1P2K1 & 90 & 22.5 & \\
\hline 14 & N2P1K1 & 180 & 11.25 & \\
\hline
\end{tabular}

\subsection{Data processing}

Data were analyzed using Microsoft Excel 2007 and SAE 5.10

\section{Results and Analysis}

\subsection{Effects of different fertilization on yield of sweet corn}

The result showed that the yield of sweet corn was significantly affected by different amounts of fertilizer and different amounts (Tab. 2). Except for treatment 8, other treatments increased yield compared with non fertilization (treatment 1). Treatment 7 produced the highest yield of 13477.5 $\mathrm{kg} / \mathrm{hm}^{2}$, followed by treatment 9 was $13171.5 \mathrm{~kg} / \mathrm{hm}^{2}$. The yield of treatment 9 and treatment 7 increased respectively by $23.98 \%$ and $21.17 \%$ compared with non fertilization plot. The yield of treatment 8 was minimum as $10806 \mathrm{~kg} / \mathrm{hm}^{2}$. Yield of treatment 8 increase $-0.6 \%$ compared with non fertilization treatment. Except for treatment 3 and treatment 5, other treatments showed significant increase in yield compared with non fertilization (treatment 1). The total nutrient content of $\mathrm{N}_{3} \mathrm{P}_{2} \mathrm{~K}_{2}$ was the highest (Tab. 1), but the yield was not the highest. Explain the law of diminishing returns between fertilization and yield of sweet corn. The mathematical model of yield and fertilizer was obtained by simulating the fertilizer effect with regression model:

$$
\mathrm{y}=730.19+14.65 \mathrm{~N}-0.81 \mathrm{~N}^{2}-13.67 \mathrm{P}+30.08 \mathrm{P}^{2}+17.78 \mathrm{~K}-15.92 \mathrm{~K}^{2}-5.90 \mathrm{NP}+3.85 \mathrm{NK}+11.21 \mathrm{PK}
$$

Multiple correlation coefficient $\mathrm{R}=0.8433^{*}$ ， Decision coefficient $=0.9898^{*} \mathrm{~F}=42.9649^{*}$ 。 The results showed that the yield of 14 treatments had significant difference. The application of $\mathrm{N}, \mathrm{P}$ and $\mathrm{K}$ increased the yield of sweet corn significantly. By using the above mentioned fertilizer effect model, the best yield is $\mathrm{Y}=12367.5 \mathrm{~kg} / \mathrm{hm}^{2}$.

The single factor effect analysis is used to obtain the yield of each factor under different levels through the main effect model. When the two factors are zero, a single factor effect model is obtained:

$$
\begin{aligned}
& \mathrm{y}=742.115+7.5942 \mathrm{~N}-0.2062 \mathrm{~N}^{2} \\
& \mathrm{y}=839.035-100.935 \mathrm{P}+57.5556 \mathrm{P}^{2} \\
& \mathrm{y}=732.24+102.2267 \mathrm{~K}-19.1111 \mathrm{~K}^{2}
\end{aligned}
$$

From the coefficient of the first term, the influence on yield is $K>N>P$. From the two item, the absolute value is $\mathrm{P}>\mathrm{K}>\mathrm{N}$. The treatments of nitrogen, phosphorus and potassium showed that corn yield increased first and then decreased with the increase of fertilizer amount. Combining the relative yield of $\mathrm{N}, \mathrm{P}$ and $\mathrm{K}$, we can see that potassium fertilizer is the key control factor in the production of sweet corn, followed by nitrogen fertilizer. 
TABLE2. The yield of sweet corn

\begin{tabular}{|c|c|c|c|c|c|c|}
\hline \multirow[b]{2}{*}{ Number } & \multirow[b]{2}{*}{ Treatments } & \multicolumn{2}{|c|}{ Yield } & \multirow[b]{2}{*}{$(\mathrm{Kg} / \mathrm{hm} 2)$} & \multirow[b]{2}{*}{ $\pm \%$} & \multirow[b]{2}{*}{ Yield order } \\
\hline & & \multicolumn{2}{|c|}{$\begin{array}{c}(\mathrm{Kg} / \mathrm{plot}) \text { Significance } \\
\text { difference }\end{array}$} & & & \\
\hline 1 & & 21.73 & ghEF & 10870.5 & & 13 \\
\hline 2 & NOP0K0 & 22.53 & fghDEF & 11271.0 & 3.68 & 12 \\
\hline 3 & N0P2K2 & 22.56 & fghDEF & 11286.0 & 3.82 & 11 \\
\hline 4 & N1P2K2 & 25.13 & abcdABC & 12657.0 & 15.65 & 5 \\
\hline 5 & N2P0K2 & 23.43 & efgCDEF & 11721.0 & 7.82 & 10 \\
\hline 6 & $\begin{array}{l}\mathrm{N} 2 \mathrm{P} 1 \mathrm{~K} 2 \\
\mathrm{~N} 2 \mathrm{P} 2 \mathrm{~K} 2\end{array}$ & 24.93 & bcdeABCD & 12471.0 & 14.73 & 6 \\
\hline 7 & $\mathrm{~N} 2 \mathrm{P} 3 \mathrm{~K} 2$ & 26.94 & $\mathrm{aA}$ & 13477.5 & 23.98 & 1 \\
\hline 8 & $\mathrm{~N} 2 \mathrm{P} 2 \mathrm{~K} 0$ & 21.6 & $\mathrm{hF}$ & 10806.0 & -0.6 & 14 \\
\hline 9 & $\mathrm{~N} 2 \mathrm{P} 2 \mathrm{~K} 1$ & 26.33 & $\mathrm{abAB}$ & 13171.5 & 21.17 & 2 \\
\hline 10 & $\mathrm{~N} 2 \mathrm{P} 2 \mathrm{~K} 3$ & 24.5 & cdeBCD & 12262.5 & 12.75 & 7 \\
\hline 11 & $\mathrm{~N} 3 \mathrm{P} 2 \mathrm{~K} 2$ & 24.07 & defBCDE & 12040.5 & 10.76 & 8 \\
\hline 12 & N1P1K2 & 23.97 & defBCDEF & 11991.0 & 10.31 & 9 \\
\hline 13 & $\begin{array}{l}\text { N1P2K1 } \\
\text { N2P1K1 }\end{array}$ & 25.88 & $\mathrm{abcABC}$ & 12946.5 & 19.1 & 3 \\
\hline 14 & $\mathrm{~N} 2 \mathrm{P} 1 \mathrm{~K} 1$ & 25.35 & $a b c A B C$ & 12681.0 & 16.66 & 4 \\
\hline
\end{tabular}

Note: the capital letters indicate the significant difference at $1 \%$ level.

\subsection{Effects of lack of fertilizer on yield of sweet corn}

Treatment 1 , treatment 2 , treatment 4 , treatment 6 , treatment 8 are no fertilizer plot, nitrogen deficiency plot, phosphorus deficiency plot, the best fertilization plot, potassium deficiency plot respectively. Soil fertility contribution rate $=$ yield of no fertilizer plot $\div$ yield of optimum fertilization plot $\times 100 \%$. By Table 2 , it can be calculated that the land fertility contribution rate is $87.16 \%$. It shows that the contribution rate of fertilizer to yield is only $12.84 \%$ at the local fertility level. The results showed that soil fertility was higher, and the yield increasing effect of fertilization is low. Relative yield = yield of deficit plot $\div$ yield of optimum fertilization plot $\times 100 \%$. The relative yield of nitrogen deficiency (treatment 2) is $90.37 \%$. It shows that the contribution rate of nitrogen fertilizer to yield was $9.63 \%$ under local fertility level. The relative yield of P deficiency (treatment 4 ) is $100.80 \%$, It shows that the contribution of $\mathrm{P}$ fertilizer to yield is weak under local fertility level. The relative yield of potassium deficiency (treatment 8 ) was $86.46 \%$. The contribution rate of potassium fertilizer to yield was $13.54 \%$ under local fertility level. This shows that under the experimental conditions, the three elements of nitrogen, phosphorus and potassium have the most obvious effect of potassium production, the yield increasing effect of nitrogen was the second, but the yield increasing effect of phosphorus was not significant (Fig.1). Potassium fertilizer is the key factor to determine the yield of local sweet corn.

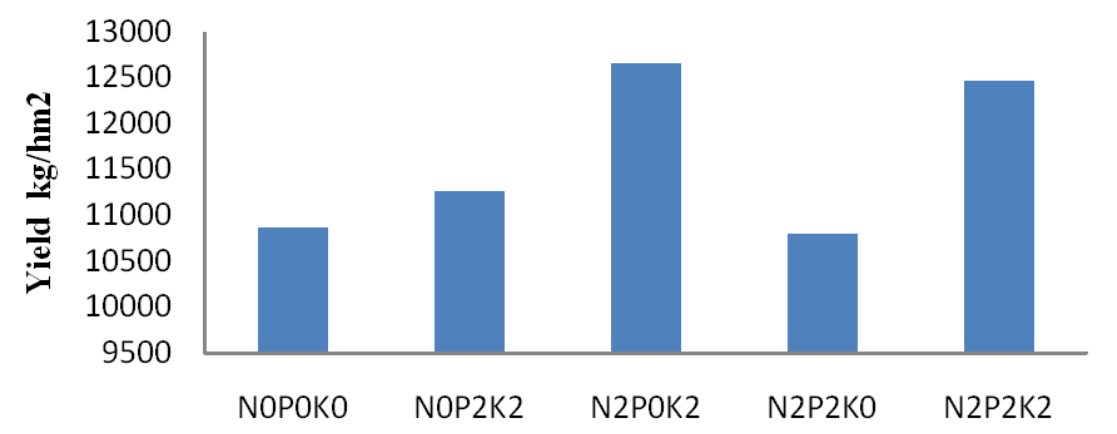

FIGURE 1. Effects of lack of fertilizer on yield of sweet corn

\section{Results and Discussion}

Based on the regression analysis of yield and fertilizer amount of sweet corn, the two times fertilizer effect function of nitrogen, phosphorus and potassium three variable: was established: 
$\mathrm{y}=730.19+14.65 \mathrm{~N}-0.81 \mathrm{~N} 2-13.67 \mathrm{P}+30.08 \mathrm{P} 2+17.78 \mathrm{~K}-15.92 \mathrm{~K} 2-5.90 \mathrm{NP}+3.85 \mathrm{NK}+11.21 \mathrm{PK}(\mathrm{R}=0.84)$ .The optimum application amount of nitrogen, phosphorus and potassium fertilizer were $156 \mathrm{~kg} / \mathrm{hm} 2,12$ $\mathrm{kg} / \mathrm{hm} 2$ and $30 \mathrm{~kg} / \mathrm{hm} 2$ respectively when the yield of sweet corn was $12367.5 \mathrm{~kg} / \mathrm{hm}^{2}$ in this region. The fertilizer amount of nitrogen, phosphorus and potassium was lower than that in Guangzhou city ${ }^{[6]}$. This may be because the experimentation area has higher soil fertility.

Research shows that the contribution rate of soil fertility was $87.16 \%$, the contribution rate of fertilizer to yield is only $12.84 \%$. It shows that sweet corn yield had a greater dependence on soil basal fertility. At the local fertility level, the contribution rates of nitrogen, phosphorus and potassium fertilizer to yield were $9.63 \%,-0.80 \%, 13.54 \%$, respectively. Therefore, potassium fertilizer plays a decisive role in sweet corn yield under this soil fertility level. The soil phosphorus supplying capacity was higher in the experimental soil. Excessive application of phosphate fertilizer will lead to negative returns. This is consistent with the trend of the test results in Guangdong ${ }^{[6]}$. The soil in sweet corn area of Guangdong is relatively deficient in nitrogen and potassium, but the content of phosphorus is relatively high. The fertilization efficiency of sweet corn in Guangdong is higher.

The results of field experiments showed that the order of the effects of lack of fertilizer on the yield of maize was $K>N>P$. In the 3 fertilizers of nitrogen, phosphorus and potassium, the 2 fertilizers remain unchanged, the yield of maize increased first and then decreased with the increase of fertilizer use. This result is consistent with the results of the study of common maize in Shanxi ${ }^{[7]}$. In order to improve the economic returns of farmers, fertilizer should be used reasonably in production.

\section{Acknowledgments}

This work was financially supported by Hubei science and technology support project (2015BBA151).

\section{References}

[1]. W.T. SUN and R.WANG, Journal of Mire Sciences 16, 109-111(2008)

[2]. P.Y. ZHANG, J.F. HE, F.S.MENG, Journal of Jiangsu Sci.42, 119-122 ( 2014)

[3]. S.S. BI, G.Y. ZHANG, P.F. YANG, Chinese Journal of Tropical Agri., .35, 7-11(2015)

[4]. X.S. SEN, S.H. CHENG, H.L. CHENG, Journal of Agricultural Sciences, 25,2132-2137 (2012)

[5]. J.J. HU, Y.Q. ZHANG, X.F. WEN, Research of Soil and Water Conservation,18,89-949（2011）

[6]. B.G. ZHANG, Q.LI, Q.X. CHEN, Journal of Guangdong Agri. Sci., 20, 67-70(2013)

[7]. G.M. LIANG, L.L. LI, Journal of Anhui Agri. Sci., 42, 8573-8574(2014) 